\title{
Proper names in German-language mass media (prospects in teaching methodology and new opportunities)
}

\author{
Irina Maslova ${ }^{1 *}$ \\ ${ }^{1}$ Moscow State Linguistic University (MSLU), 38 Ostozhenka St., Moscow; Peoples' Friendship \\ University of Russia (RUDN University), Faculty of Low, 6 Miklukho- Maklaya St, Moscow, \\ 117198, Russian Federation
}

\begin{abstract}
The research covers semantic and pragma-stylistic features of onomastic units in German-language mass media, as well as the peculiarities of their functioning and impact on the reader, their prospects in the process of teaching a foreign language (in the terms of stylistic analysis of media texts).
\end{abstract}

\section{Introduction}

It is known that linguistic positioning in the language system and extralinguistic factors, which influence the semantic structure formation of proper names (PNs) and their functioning, account for peculiar features of any onomastic material. Scientists unanimously affirm that PNs have a particular place among other units of noun class (works by O. Jespersen, J. Kurylowicz, A.A. Beletskiy, A.A. Reformatsky, B. Russell, A.V. Superanskaya, V.A. Nikonov, V.I.Suprun, etc.). The following idea of V.A. Nikonov is widely recognized: "Proper names shape a certain subsystem in the language where even basic language laws are refracted specifically, and its own patterns appear, which do not exist in the language outside this subsystem" [1].

A. V. Superanskaya also points out the substantial nature of PNs: "Even the most "pure" linguistic study of names cannot go solely beyond the abilities of language, and linguists should always keep in mind extralingual associations of proper names. Here social factors take the first place by right, being in close connection with history, politics, economy $\langle\ldots\rangle$. Factors that determine ideology of the given society necessarily influence names" [2].

\section{Objects and Methods}

The object of this research is the titles of the German-language media as a special category of onomastic units.

The main research method of work is the descriptive method, implemented in the form of a combination of such techniques as:

\footnotetext{
*Corresponding author: irvolga1973@yandex.ru
} 
a) methods of observation, comparison, generalization and classification of the analyzed material;

b) receiving contextual interpretation;

c) reception of quantitative calculations.

The sources of the study were materials from German-language periodicals (newspapers in Germany) for 2019.

\section{Results}

The onomastic usage in German media texts confirms the above. Thus, in the newspaper Die Welt (12/11/2019) we can witness an onym in the title Die vereinigten Alten von Amerika. The nature of this language unit is obvious: it is derived from a stable lexical unity of nonphraseological kind (Klasse IV - lexikalische Einheiten (FWK nichtphraseologischen Typs/ under the classification by I.I. Chernishyova) [3].

It must be mentioned that in the Russian language the initial noun phrase The United States of America (Vereinigten Staaten von Amerika) belongs to the core of onomastic vocabulary, meaning a geographical object and being a toponym (namely, anthroponyms and toponyms form the core of onomastic field in any language). Basically, the three-component structure of the Russian anthroponymic model (Alexander Sergeyevich Pushkin), in our opinion, also gives ground to refer the noun phrases to the class of onyms - "words and word combinations that serve to emphasize and identify single objects (animate and inanimate), express single terms and general ideas about these objects in language, speech and culture of peoples" [4]. As such complex (dismembered) in their structure lexical unities are characterized by both individual cohesion of components and their independent lexical meaning simultaneously, they are distinguished through stability (Stabilität) and reproducibility (Reproduzierbarkeit), by not through idiomaticity (Idiomatizität); based on it they could be regarded as phraseological, but not onomastic units. However, the already mentioned I.I.Chernishyova does not relate lexical unities to phraseology, as the composition of their components lacks semantic transformation. It should be emphasized that the structural-semantical classification of phraseological units in the German language by I.I. Chernishyova is widely recognized in German studies. The author took the principles of her classification from the famous classification by the academician V.V. Vinogradov. Though, not all his statements can be applied to German phraseologisms, as phraseological units in German tend to be more flexible in regards to their components than it is in Russian (the classification by I.I. Chernishyova also takes into account this fact, being distinguished through more elaborate division of the German language phraseological field). The phraseological concept of the latter defines phraseologisms as stable word combinations of various structural types with unified cohesion of components, the meaning of which emerges in the process of full or partial semantic transformation of the component composition. Consequently, if the main condition - "semantic transformation of the component composition" - is not fulfilled - lexical unities cannot be considered phraseologisms, and it brings us to the conclusion that noun phrases have a similar language status in Russian and German studies. Thus, title PNs in German media texts are onomastic units defined by a complex grammatical structure and a specific (multidimensional) pragmatic (connotativestylistic) meaning, performing functions of sense- and text formation and implementing the nominative (nominative-differentiating) function of the language.

We can prove the above if we analyze the already mentioned example - Die vereinigten Alten von Amerika. Having verified the language status of noun phrases, let us look at the semantic and pragma-stylistic potential of onyms. The article by Hans Stein entitled «Die vereinigten Alten von Amerika» is satirical: the author ridicules the age of world politicians, particularly those in the USA, using the term "gerontocracy". In his opinion, it is namely the age of 
politicians in each country that defines the programs of candidates running for presidency or for positions in the leading parties (for example, Donald Trump at his 73 asserts the importance of improving healthcare in the country). Such vereinigten Alten von Amerika do not pay attention to the real problems of younger population (statistically, average age of a US citizen is 37,6 , while average age of a US politician is 75). According to H. Stein, such state of things poses a serious threat for the future of world powers: nowadays financiers and businessmen in different countries are mostly young people of about 35 (on average). And this young promising and talented people (like Mark Zuckerberg), capable of changing political systems, do not go to elections and do not participate in governing the state. Consequently, not being listened to, such young people give precedence to "gerontocrats", condemning states to demographic collapse.

However, H. Stein not only ridicules the American problem of "gerontocracy", but also criticizes German leaders, who follow in the footsteps of Americans. He reminds about the active leadership of young people in other European countries, in Latin America, and boldly claims that time has come to change the existing way of life.

It is absolutely clear that the onym Die vereinigten Alten von Amerika plays an important part in the process of interpreting the original text by H. Stein. First, the pun successfully created by the author (replacing one of the components in the familiar toponym the United States/Old of America) puts forward a whole complex of denotative-significative (core, categorical and sub-categorical semes) components inside the meaning of the proper name: "object/animate - inanimate"; for an animate object - "man/age". Second, semantic transformations of the PN components (and in this case we can speak about the signifier of this onym namely in the context of the word Alten) have actualized connotative semes in the noun phrase; semes, presenting the implication of its meaning. The discourse-contextual extensions of the PN Die vereinigten Alten von Amerika, as well as linguo-literary analysis let us grasp the following idea: the "inviolability" of America, which used to be a great world power, cracked and is being questioned nowadays. If in previous times the toponym The United States of America was pronounced with awe, bringing up a whole range of strong associations, now native speakers from different countries "shatter" the semantic structure of this lexical unit with pleasure, allowing the swap of components in the noun phrase. Third, such changes turn out to be quite eloquent: not States, but The Old, which gives additional features to the object of nomination. Not a world power, but an old-fashioned, lagging behind state, the health of which (in conditions of gerontocracy) arouses great concern in the international community.

It should be mentioned that we can continue the analysis of semantic and pragma-stylistic components of the PN Die vereinigten Alten von Amerika, because its contextual meaning (including media texts) varies to a large extent. We suppose that its potential is open and depends on many factors - linguistic and extralinguistic. The first ones include the presence of close and general context (under B.A. Larin's terminology), as only in close and notable connection with it the PN starts working in spoken and written discourse. Extralinguistic factors, which influence the perception and interpretation of pragma-stylistic (implicit, periphery) components in the PN meaning, include onomastic knowledge that interlocutors possess (activated and potential). In our opinion, such knowledge makes up a specific competence that native speakers have - onomastic competence [5]. Three levels of the reader's onomastic competence are singled out [ibid]. The levels of such competence, which a lingual personality possesses, are based, as a rule, on linguo-cultural information, pragmatic and probabilistic semes of imaginative and associative origin, both shared by each member of a lingual community at a particular stage of its development and individual (depending on age, social status, educational level and upbringing of the reader, etc.). It is important that PNs in texts (including media) present "a concentrated expression of cultural realities" (V.I. Karasik). Onomastic competence of a lingual personality includes precedent texts (U.N. 
Karaylov), or "obligatory" works of art (E.M. Vereshyagin, V.G.Kostomarov), meaning those pieces of literature, painting, sculpture, architecture, music, folk culture, which any native speaker is familiar with.

\section{Conclusions}

Thus, semantical-stylistic transformations of PNs in texts lead to the fact that such items become undoubted signs of textual reality. They participate in the dialogue not only between the author and the reader, but also between the author and the whole contemporary and preceding culture (M.M. Bakhtin), as due to their pragmatic informativity, they often act as markers of allusions, citations and other inclusions (which H. Stein showed in his article in the newspaper «Die Welt»). PNs used in titles (in a strong textual position) contribute to revealing the main topic of a particular work, as well as to the actualization of the author's concept and the general prospection of the text (Politik nach Kissenlagel Mach Mint! I Rückzug - was hat Sahra Wagenknecht jetzt vor?/ Richtig erben und vererben / Stuttgard ist ein starker Standort / Wenn Schlafmangel ängstlich macht / Wer tanzt, lebt gesünder and so on). It means that even in our digital era analyzing onomastic material remains an important step of working with texts (both in native and in foreign languages), and studying onyms obviously facilitates the formation of "a second lingual personality", which has always been a final aim for language learners in the process of studying any foreign language.

\section{Acknowledgments}

This paper was financially supported by the Russian Foundation for Basic Research, project № 20-012-22046.

\section{References}

1. V.A. Nikonov, Name and society, Moscow, (1974)

2. A.V. Superanskaya, Antrophonym., Moscow, (1970)

3. I.G. Olshanskiy, A.E. Guseva, Lexicology: Contemporary German. Lexikologie: Die deutsche Gegenwartssprache, Moscow, (2005)

4. N.V. Podolskaya, Linguist. Encyclop. Dictionary, Moscow, (1990)

5. I.B. Voronova, The function of text formation of fictional proper nouns (based on epic

literature of 19-10 centuries): Phd thesis., Volgograd, (2000) 